\title{
A Study on the Innovation of Chinese Linguistics Courses for International Education of Chinese Language
}

\author{
Jie Bai \\ Xi'an Peihua University, \\ Humanities School, \\ Xi'an, China
}

\begin{abstract}
At present, there are still some problems in the courses of Chinese Linguistics for international education of Chinese language in Chinese undergraduate education. The article discusses the innovative ideas of teaching reform from teaching objectives, teaching contents and teaching methods, and then makes an overall outlook on the post-reform teaching effect, which is expected to meet the needs of training on professionals for International Education of Chinese language.
\end{abstract}

Keywords-International Education of Chinese Language; Chinese Linguistics Courses; teaching innovation; classification teaching method

\section{INTRODUCTION}

In China, the development of international Chinese language teachers at the undergraduate level is mainly achieved through the specialty setup of International Education of Chinese language in colleges and universities. This specialty aims to cultivate the professionals who not only master the knowledge of Chinese language, Chinese culture and crosscultural communication skills, but also are proficiency in the second language teaching skills. Under the guidance of this strategy, the curriculum setup of this specialty is also divided into four modules: Chinese Linguistics, Literature and Culture, Teaching and Foreign Language. Chinese Linguistics Courses include three core courses: Modern Chinese, Ancient Chinese and Introduction to Linguistics. For a long time, there are many problems in these courses, which exist mainly in the following areas.

\section{A. The teaching objectives cannot highlight the specialty characteristics}

The three language courses set up by the specialty are also available in the specialties of Chinese Language and Literature, Journalism and Art of Broadcasting and Hosting, etc. If the objectives of training on professionals in different specialties are not the same, the teaching objectives of the courses are certainly not the same. However, the reality is that the teaching objectives of these three courses in different specialties make very little difference. [1]

Take "Modern Chinese" as an example, according to educational circles, the current objectives of the course can be summarized as "three basics" and "three abilities". "Three basics" refers to the basic theory, basic knowledge and basic skills. "Three abilities" refers to the ability to understand, analyze and apply.

The syllabus has universally significance to the specialty "Modern Chinese", but lacks pertinence to specific specialties. Therefore, in development of "Syllabus for Modern Chinese" for International Education in Chinese, we should pay attention to combine the reality of international education in Chinese and make some thoughts on teaching objectives, teaching content, teaching methods and assessment methods. If we simply use the same teaching syllabus, the same textbook, the same lesson plans and the same assessment method, then we cannot meet the professional requirements.

\section{$B$. The textbook content is redundant, obsolete and repeated}

Since the establishment of TCFL ( revised as "International Education of Chinese language " in 2012) in China, the textbooks selected for the language courses of this specialty are nothing more than the following: "Modern Chinese" under the general editorship of Huang Borong and Liao Xudong used for the Modern Chinese courses; "Linguistics Compendium" under the general editorship of Xu Tongqiang and Ye Feisheng used for the Introduction to Linguistics courses; "Ancient Chinese" under the general editorship of Wang Li or Guo Xiliang used for the Ancient Chinese courses. The contents of these materials are complicated. The "Modern Chinese" edited by Huang Borong and Liao Xudong is now revised and enlarged for five editions. Now the textbook becomes heavier and thicker, in which, however, says nothing about how to deal with the practical problems for foreigners to learn Chinese, so it is difficult to solve the actual teaching problems, let alone to meet the training requirements on professionals for International Education in Chinese. The content of "Linguistics Compendium" edited by $\mathrm{Xu}$ Tongqiang and Ye Feisheng is divided into two sections: the nature and structure of language; the development and evolvement of language. For decades, the theoretical framework of structuralism proposed more than a century ago has been still in use in the textbook after several revisions, but the results of more mature and recent research on linguistic development is rarely introduced into teaching materials.

Not only that, there are repetitive contents in these courses. For example, refer to the figure below for the overlapping 
contents of "Modern Chinese" edited by Huang Borong and Liao Xudong and "Linguistics Compendium" edited by $\mathrm{Xu}$ Tongqiang and Ye Feisheng.

TABLE I. OVERLAPPING CONTENTS OF "MODERN CHINESE" EDITED BY HUANG BORONG AND LIAO XUDONG AND "LiNGUISTICS COMPENDIUM" EDITED BY XU TONGQIANG AND YE FEISHENG.

\begin{tabular}{|c|c|c|}
\hline Table Head & Modern Chinese & $\begin{array}{c}\text { Linguistics } \\
\text { Compendium }\end{array}$ \\
\hline Phonetics & $\sqrt{ }$ & $\sqrt{ }$ \\
\hline Vocabulary/ Meaning & $\sqrt{ }$ & $\sqrt{ }$ \\
\hline Grammar & $\sqrt{ }$ & Words/Chinese \\
characters
\end{tabular}

In addition, when teaching the formation of character, we may talk about the "the six categories of Chinese characters" in the "Ancient Chinese" course and talk about "'the four new categories of Chinese characters" in the "Modern Chinese" course. If teachers cannot skillfully deal with this situation, it will make students tired.

\section{The teaching methods are outdated}

The teaching objectives and teaching content often determine the teaching method. [2] If there is no clear teaching objectives in teaching, teachers often cannot make appropriate choice of teaching content and may simply use the same textbook, method and way of assessment regardless of the specialties, thereby one can imagine the teaching effects in this situation. At present, the linguistics courses of this specialty in China are basically the "cramming education", in which teachers are tired of teaching and students are tired of learning. After a few classes, students' interests in linguistics also disappeared. This kind of teaching method greatly bound the students' creative ability. The students will only learn the knowledge and the problem taught in the book and the classroom, but they will be bewildered when they encounter the new questions.

\section{CURRICUlum REFORM AND INNOVATION}

In view of the current situation above, the Chinese Linguistics Courses for International Education of Chinese language must clarify the teaching objectives as soon as possible. In addition, the reform and innovation of teaching content and teaching methods are also imperative.

\section{A. Clear teaching objectives}

In the design of the syllabus, we must face up to the differences among the three linguistics courses in different specialties. For the specialty of International Education in Chinese, the teaching objectives must accurately grasp the uniqueness and reality of teaching Chinese as a foreign language regardless of what courses are.

Take "Introduction to Linguistics" as an example, its teaching objectives should reflect the content and requirements of teaching Chinese as a second language, which has a theoretical significance to the language teaching. It includes: I. Master the nature of language, structure rule of language and general law of language development and evolution and understand the relationship between the language and other related phenomena. Grasp the phonetics, vocabulary, grammar, character and pragmatic rules and characteristics; II. Understand the universality and differences between Chinese and other languages and be familiar with the focus and difficulties of teaching Chinese as a foreign language; III. Use the linguistic theories to explain various language phenomena in Chinese analyze various problems of foreigners in learning Chinese and make a correct explanation.

\section{B. Reform of teaching content}

1) Make selection and update of the contents in textbooks. Take "Modern Chinese" as an example, on the premise of the five major parts of "Phonetics", "Character", "Vocabulary", "Grammar" and "Rhetoric" in the textbook, the contents in the teaching materials should be more meticulous and targeted to solve all the issues involving each of the knowledge points that are likely to cause the wrong words. In the existing textbooks, "Modern Chinese" edited by Qi Huyang is a teaching material written according to the purpose and curriculum of International Education in Chinese. The book includes six chapters-introduction, phonetics, Chinese characters, vocabulary, grammar and pragmatics. Its outstanding features are both theoretical and practical: on the one hand, it systematically introduce the knowledge on modern Chinese, on the other hand it focuses on combination with modern language situation and reality of teaching Chinese as foreign language. All the chapters are equipped with relevant language standardization and teaching summary, which introduces the latest research results and trends and explains the basic principles and difficulties of basic elements of language in teaching Chinese as foreign language.

2)Skillfully deal with the duplicate contents. Also on teaching the "Phonetics", the "Modern Chinese" should focus on knowledge in pronunciation of mandarin Chinese, combination rules of initials, finals and tones and spelling rules of Chinese, and should focus on the promotion of Mandarin and the standardization of pronunciation with the phoneme theory less involved. The "Introduction to Linguistics" should focus on teaching the phonetic nature, pronunciation characteristics of vowel and consonant. The International Phonetic Alphabet is the logograms of vowel and consonant, so it is one of the key teaching points. As for the "phoneme" theory, it should be taught in detail. The phoneme is a reflection of the natural properties of phonetics, while phoneme is the embodiment of social properties of phonetics, so, through teaching, we shall make students understand that it is not enough if we only study the phoneme but not involve the phonemes.

3) Increase the proportion of courses and pay attention to the transition between courses. The curriculum setup of International Education in Chinese is mainly divided into four modules: Chinese Linguistics, Literature and Culture, Teaching and Foreign Language. Some colleges and universities have appropriately increased the proportion of foreign language learning, in addition to some English courses and "second language" courses, which helps students to do bilingual teaching. On the whole, however, it greatly compressed the class periods of Chinese Linguistics Courses and is bound to 
affect students on their study of Chinese ontology knowledge and other courses, which is difficult to meet the needs of training on professionals for this specialty. Therefore, we should try to leave a large space for Chinese Linguistics Courses.

4)We should also pay attention to the order for opening the courses "Linguistics", "Modern Chinese" and "Ancient Chinese". At present, the colleges and universities basically use two methods on the order of curriculum setup: open the "Introduction to Linguistics" course in the first year of the college, and then open in succession the "Modern Chinese" and "Ancient Chinese" courses. Another method is just the opposite. From a scientific point of view, the "Introduction to Linguistics" course belongs to the scope of general linguistics, which has guiding significance to other linguistics courses, so it should be set up first. It is mentioned in the Preface of the "Linguistics Compendium" edited by Xu Tongqiang and Ye Feisheng that the "Introduction to Linguistics" course is the antecedence among all courses..., which provides the necessary theoretical knowledge for the study of various linguistics courses, but also lays the foundation for the future study of language theory courses. "However, the actual situation is: the "Introduction to Linguistics" is a highly theoretical and too abstract course compared with other courses, in which students have little interest and the teaching effect is not good either. Therefore, the more appropriate approach is: set up "Modern Chinese" and "Ancient Chinese" first and then set up "Introduction to Linguistics" after the students have a certain knowledge of specific linguistics. On the one hand, it is easy for students to accept and understand the theory of general linguistics from concrete to abstract; on the other hand, with knowledge on general linguistics, students will have more indepth understanding when they come back to think about "Modern Chinese", "Ancient Chinese" and even some knowledge about foreign language.

\section{Reform and innovation of teaching methods}

Most of the past curriculum reform of linguistics courses were all carried out from the perspective of teachers. Shao Jingmin argues that "the teaching effect of the course "Modern Chinese" to a large extent depends on the teacher's teaching methods and teaching art. The teaching result will be not satisfactory, if an excellent textbook is taught not well. As for a more passable textbook, if the teacher makes some adjustments and complement on the contents with wonderful teaching, he will make students benefit a lot.” [3] There are too many kinds of thoughts, but now we should think about what students want to learn in the classroom, since only the student-based classroom teaching can really mobilize the enthusiasm of students and fundamentally relieve the bottlenecks of teaching in linguistics courses.

A new student-centered teaching model - classification teaching method - is worth learning from. This kind of teaching method originated from American colleges and universities, and its essence lies in respecting students' interest, specialty, career tendency and other factors, so that students can give priority to their learning content, learning style and learning level in the relatively closed space. It has the following characteristics:
1) Promote communication between teachers and students with advanced teaching platform.

The syllabus includes teaching objectives, teaching methods, assessment methods, teaching content, reference materials and other contents and is generally not available to students. Now, the details of the contact of the teacher is added in the syllabus provided to students, so that the students will know all aspects of the course, and more importantly, to promote timely and effective communication between teachers and students. This communication can not only be completed in class, but also can be achieved through the Internet after class. The WeChat is a very good platform, and with the function of WeChat Moments, we can push some information related to the curriculum to the students, so that the teachers and students will have a more convenient communication.

2) Teach step by step with all teaching steps linked with one another.

In order to ensure the successful completion of the teaching contents, teaching processes in class are all linked with each other and the entire teaching runs through the flow of preview lectures - practice - review - examination. Each teaching step will be managed and controlled by the teacher in their own way. For example, the examination means may include the following:

Exams in class. After explaining a certain knowledge point or organizing the discussion on an important question, the teacher will ask questions at random and ask the students to reply in a certain period of time and then collect them for discussion. For example, in the "Introduction to Linguistics" class, after the teacher explains the International Phonetic Alphabet, he should then ask the students to write their own name with the IPA within three minutes. This method can immediately reflect the degree of students to grasp the knowledge, so as to remind teachers to improve their teaching strategies at any time and enhance their teaching effectiveness. This kind of test results can also be included in the usual results to encourage students to listen carefully to the teacher in every class.

Group discussion in class. The group discussion in class often occurs before teaching a chapter. The teacher shall ask questions first and then divide the students into a number of groups. Students will be required to prepare the discussion materials after class and have the group discussion in class with the final submission of the discussion results. Teachers should grade them according to specific performance of students and eventually make a general guidance and evaluation on the discussion results of the students.

Major assignments after class. Combined with teaching content, teachers will give students a few assignments. These assignments are diverse. In the case of the course "Introduction to Linguistics", a teacher can arrange four assignments for one semester, namely, writing a reading note of Saussure's "Course in General Linguistics"; writing a paper on the topics involving language and culture with a self-designed title; marking the ancient poem "On the Stork Tower" with the IPA (narrow transcription); listing the new words of the year and explain the usage and thinking about the characteristics of the new words. 
After the teacher reads over the assignments, the four performance results will be included in the system final results.

\section{Diversified assessment methods}

The purpose of the diversified assessment methods is to cultivate the students' self-study ability and let the teachers make more objective and scientific evaluation on the students' whole-term study. Take the course "Modern Chinese" as an example, the way of assessment can be designed as: attendance $(10 \%)$, exams in class (10\%), group discussions $(10 \%)$, major assignments (20\%) and final examinations (50\%).

\section{E. The overall outlook after the reform}

Through the above reforms, we hope to achieve the following objectives.

On the one hand, we hope to make the overall improvement of students' interest in learning, so that the students are able to understand the basic position of Chinese Linguistics Courses in International Education of Chinese language. These courses tell us "what to teach", which is the cornerstone for the existence of this specialty. Through the reform, students will change from the passive acceptance of knowledge in the past into the selfdirected learning now. On the other hand, the overall improvement of language teaching ability of students has been achieved. In the past, students would look for some references or information when they found errors in learning or teaching practice, for example, by using "Modern Chinese Dictionary" and "Eight Hundred Words of Modern Chinese" and other reference books or via online collection of relevant information.
However, they will be stagnant to some of the problems they have encountered that cannot be solved by the reference books. Now, through the reform, I hope that students will be able to make classification, comparison, analysis and summary on the errors and ultimately find a solution to them without use of the reference books.

\section{CONCLUSION}

Chinese Linguistics Courses are the basic courses of International Education in Chinese. It solves the problem of "what to teach". Compared with the literature and culture courses, linguistics courses have never been popular with students. Therefore, it is necessary to make reflection and innovation on the teaching objectives, teaching content and teaching methods, so as to fundamentally improve the enthusiasm of students in learning, develop long-term language teaching ability, thereby laying a solid foundation for their teaching work in the future.

\section{REFERENCES:}

[1] Fu Na, “Object-Consciousness: Teaching Principle of Introduction to Linguistics for International Education in Chinese”, Journal of Beijing Institute of Education. No.2, 2014.

[2] Zeng Yiping, "Problems on Course Construction of 'Introduction to Linguistics””, Language Teaching and Linguistic Studies. No.1, 2001.

[3] Shao Jingmin, Humble Opinion on Reform of Teaching Methods of Modern Chinese, Language Planning. No.9, 1993. 